\title{
Simultaneous Measurement of Neural Activities of Acute Mouse Hippocampal Slices Using Multi-Electrode Array System and Laser Confocal Calcium Imaging
}

\author{
Yuuta Hamasaki ${ }^{\dagger \dagger}$, Natsumi Haba ${ }^{2 \dagger}$, Naoki Iwata ${ }^{2}$, Yoshiki Uno ${ }^{2}$, Minoru Saito ${ }^{1,2 *}$ \\ ${ }^{1}$ Department of Biosciences, College of Humanities and Sciences, Nihon University, Tokyo, Japan \\ ${ }^{2}$ Department of Correlative Study in Physics and Chemistry, Graduate School of Integrated Basic Sciences, Nihon University, \\ Tokyo, Japan \\ Email: ^msaito@chs.nihon-u.ac.jp
}

How to cite this paper: Hamasaki, Y., Haba, N., Iwata, N., Uno, Y. and Saito, M. (2017) Simultaneous Measurement of Neural Activities of Acute Mouse Hippocampal Slices Using Multi-Electrode Array System and Laser Confocal Calcium Imaging. Journal of Behavioral and Brain Science, 7, 6878.

https://doi.org/10.4236/jbbs.2017.72008

Received: January 20, 2017

Accepted: February 21, 2017

Published: February 24, 2017

Copyright $\odot 2017$ by authors and Scientific Research Publishing Inc. This work is licensed under the Creative Commons Attribution International License (CC BY 4.0).

http://creativecommons.org/licenses/by/4.0/

\begin{abstract}
Recently, non-invasive, real-time and multi-point measurement of neural activities has become possible by using a multi-electrode array (MEA). Another method for multi-point measurement is the fluorescent imaging technique using voltage indicator dyes or calcium indicator dyes. Especially, calcium imaging using fluorescent calcium indicator dyes is often more useful, because they exhibit larger changes in the fluorescence intensity than voltage indicator dyes and their fluorescence changes can be detect easily. Additionally, calcium signals play key roles in the brain function, such as the long-term potentiation (LTP) in the hippocampus, and calcium imaging can be a powerful tool to elucidate the brain function. In this study, we constructed a measurement apparatus combining the MEA system and laser confocal calcium imaging and simultaneously measured electric signals and calcium signals in acute mouse hippocampal slices. The obtained results showed the availability of the present method.
\end{abstract}

\section{Keywords}

Multi-Electrode Array, Laser Confocal Calcium Imaging,

Hippocampus, Acute Slice, Long-Term Potentiation

\section{Introduction}

The brain function is based on complicated interactions among electric neural activities, intracellular calcium signals, intercellular communications by neuro-

${ }^{\dagger}$ These authors contributed equally to this work. 
transmitters, and so on. In the hippocampus, the long-term potentiation (LTP), a persistent increase in synaptic strength following high-frequency stimulation of a chemical synapse, is a widely accepted cellular model for learning and memory, and an activity-dependent intracellular $\mathrm{Ca}^{2+}$ increase represents a key signal for the activation of the mechanism. At the synapse between the CA3 region and CA1 region, where the neurotransmitter is glutamate, $\mathrm{Ca}^{2+}$ influx through NMDA ( $N$-methyl-D-aspartate) receptors in postsynaptic membrane induces increases in the activity and number of AMAP ( $\alpha$-amino-3-hydroxy-5methyl-4-isoxazolepropionicacid) receptors and the quantity of released glutamate following the activation of a series of second messengers [1]. The involvement of calcium signals in the LTP mechanism was shown by using $\mathrm{Ca}^{2+}$ chelator [2] and caged $\mathrm{Ca}^{2+}$ [3], and calcium imaging technique [4] [5] mentioned below.

Electric signals in the brain can be measured by the conventional electrophysiological methods. By intracellular or extracellular recording, direct measurement from a single neuron or neural area is possible using microelectrodes. For the LTP measurement in the hippocampus, for example, electric stimulation such as the tetanic stimulation or theta burst stimulation is applied by a microelectrode inserted around the Shaffer collateral, and field excitatory postsynaptic potential (fEPSP) is extracellularly measured by another microelectrode inserted in the CA1 region.

The electrophysiological methods, however, are not suitable for measurement from many neurons or neural areas. They are also invasive and not suitable for long-term measurement. Recently, non-invasive, real-time and multi-point measurement of neural activities has become possible by using a multi-electrode array (MEA) [6] [7] [8] [9] [10]. The MEA has been also used for the LTP measurement in the hippocampus [11] [12] [13], in which some of the MEA electrodes were used for electric stimulation. Another method for multi-point measurement is the fluorescent imaging technique using voltage indicator dyes [14] [15] [16] [17] or calcium indicator dyes [18] [19]. Especially, calcium imaging using fluorescent calcium indicator dyes is often more useful, because they exhibit larger changes in the fluorescence intensity than voltage indicator dyes and their fluorescence changes can be detected easily. Additionally, calcium signals play key roles in the brain function, such as the LTP in the hippocampus, as mentioned above and calcium imaging can be a powerful tool to elucidate the brain function.

The MEA system [8] [11] [12] [13] and calcium imaging [4] [5] [19] have been individually used for multi-point measurement of neural activities in the hippocampus. In this study, we constructed the combined apparatus and simultaneously measured electric signals and calcium signals in acute mouse hippocampal slices. Here, we used calcium imaging using laser confocal microscopy which enables us to measure the calcium signals with single-neuron resolution [20] [21] [22]. 


\section{Materials and Methods}

\subsection{Chemicals}

Cal-520 AM, a fluorescent calcium indicator dye, was purchased from AATBioquest (CA, USA). All other chemicals were of the highest purity commercially available.

\subsection{Slice Preparations}

Male ddY mice (1-week-old) were purchased from Sankyo Labo Service (Tokyo, Japan). They were killed by cervical dislocation followed by decapitation. The brain was rapidly removed and placed into an ice-cold oxygenated artificial cerebrospinal fluid (ACSF) (composition in $\mathrm{mM}$ : $\mathrm{NaCl} 124, \mathrm{KCl} 5, \mathrm{CaCl}_{2} 2$, $\mathrm{NaHCO}_{3} 22, \mathrm{MgSO}_{4}$ 2, $\mathrm{NaH}_{2} \mathrm{PO}_{4}$ 1.24, glucose 10, pH 7.4, bubbled with $95 \%$ $\mathrm{O}_{2} / 5 \% \mathrm{CO}_{2}$ ). Transverse hippocampal slices (thickness $350 \mu \mathrm{m}$ ) were then prepared using a microslicer (DTK-1000, Dosaka-EM, Kyoto, Japan) in an ice-cold oxygenated sucrose solution (composition in $\mathrm{mM}: \mathrm{KCl} 2.6, \mathrm{CaCl}_{2}$ 0.5, $\mathrm{NaHCO}_{3}$ 27, $\mathrm{MgSO}_{4} 7, \mathrm{NaH}_{2} \mathrm{PO}_{4} 1.5$, ascorbic acid 0.1, sucrose 222, $\mathrm{pH}$ 7.4, bubbled with $95 \% \mathrm{O}_{2} / 5 \% \mathrm{CO}_{2}$ ) which can prevent cell damages [21]. The slices were recovered in ACSF at $30^{\circ} \mathrm{C}$ for $60 \mathrm{~min}$ and held at room temperature.

The care of animals and experimental procedures were carried out in accordance with national and institutional guidelines, and all experimental protocols were approved by Nihon University Animal Care and Use Committee.

\subsection{Laser Confocal Calcium Imaging}

The prepared hippocampal slices were stained with Cal-520. The slices were loaded for $60 \mathrm{~min}$ at room temperature with about $4 \mu \mathrm{M}$ of the dye in the presence of $0.005 \%$ Cremophor EL and $0.01 \%$ Pluronic F-127 in $4.0 \mathrm{~mL}$ ACSF. After dye loading, the slices were washed in ACSF for $30 \mathrm{~min}$. The stained slices were placed on a planar glass MEA chip mentioned below, and then the chip was placed on the stage of an upright microscope (E600FN, Nikon, Tokyo, Japan) and perfused with a modified ACSF (composition in $\mathrm{mM}: \mathrm{NaCl} 124, \mathrm{KCl} 5$, $\mathrm{CaCl}_{2} 2, \mathrm{NaHCO}_{3} 22, \mathrm{MgSO}_{4} 1.3, \mathrm{NaH}_{2} \mathrm{PO}_{4}$ 1.24, glucose 10, pH 7.4, bubbled with $95 \% \mathrm{O}_{2} / 5 \% \mathrm{CO}_{2}$ ) kept at $30^{\circ} \mathrm{C}$. They were illuminated through $10 \% \mathrm{ND}$ filter by an Ar laser (488 nm; 532-BS-AO4, Melles Griot, NM, USA). The laser power was set to $15 \mathrm{~mW}$. Then, the $520 \mathrm{~nm}$ fluorescence images were acquired through a $16 \times$ fluorescence objective (0.75 NA, S Fluor, Nikon, Tokyo, Japan), a Nipkow confocal unit (CSU-10, Yokogawa, Tokyo, Japan) and an EM-CCD camera (iXonX3 897, Andor, Belfast, UK). In each acquisition trial, consecutive fluorescence images were acquired at a rate of $150 \mathrm{~ms} /$ frame on a personal computer (PRECISION T3500, DELL). The obtained fluorescence images were analyzed with Andor Solis (Ver. 4.18, Andor, Belfast, UK).

\subsection{Multi-Electrode Array Recording}

The planar glass MEA chip used comprised 64 electrodes $(50 \times 50 \mu \mathrm{m})$ with 150 
$\mu \mathrm{m}$ spacing in $8 \times 8$ grid arrangement (MED-P515A, Alpha MED Scientific, Japan). The extracellular electric signals detected through the electrodes were amplified by 64-channel main amplifier (MED-D64A32, Alpha MED Science, Japan) and 64-channel head amplifier (MED-A64HE1S, Alpha MED Science, Japan) and acquired on a personal computer (PRECISION T1700, DELL) at a rate of $20 \mathrm{kHz} / \mathrm{channel}$. In some experiments, the electrodes were used for electric stimulation which was applied for the LTP measurement. A schematic illustration of the present apparatus is shown in Figure 1.

\subsection{Data Analysis}

We obtained raster plots from the peaks of the measured calcium signals as follows. From each pixel of the camera, the photocount was acquired as the fluorescence intensity $(F)$. The change in $F$ from the baseline was calculated as $\Delta F / F_{0}=$ $\left(F-F_{0}\right) / F_{0}$. Here, $F_{0}$ is the baseline fluorescence intensity. We next detected cell bodies in the fluorescence images by their profiles, and regions of interest (ROIs) were put on the individual cell bodies. The fluorescence intensity changes, $\Delta F / F_{0}$, of the pixels in each ROI were averaged as the calcium signals. Figure 2(a) shows a time course of the calcium signals. The peaks were detected using a custom program for MATLAB (Mathworks, Natick, NY, USA).

We also obtained raster plots from the peaks of the measured electric signals. Figure 2(b) shows a time course of the electric signals. The upwards and downwards peaks were also detected using a custom program for MATLAB (Mathworks, Natick, NY, USA).

\section{Results and Discussion}

We combined the MEA system and laser confocal calcium imaging (Figure 1) and simultaneously measured extracellular electric signals and intracellular

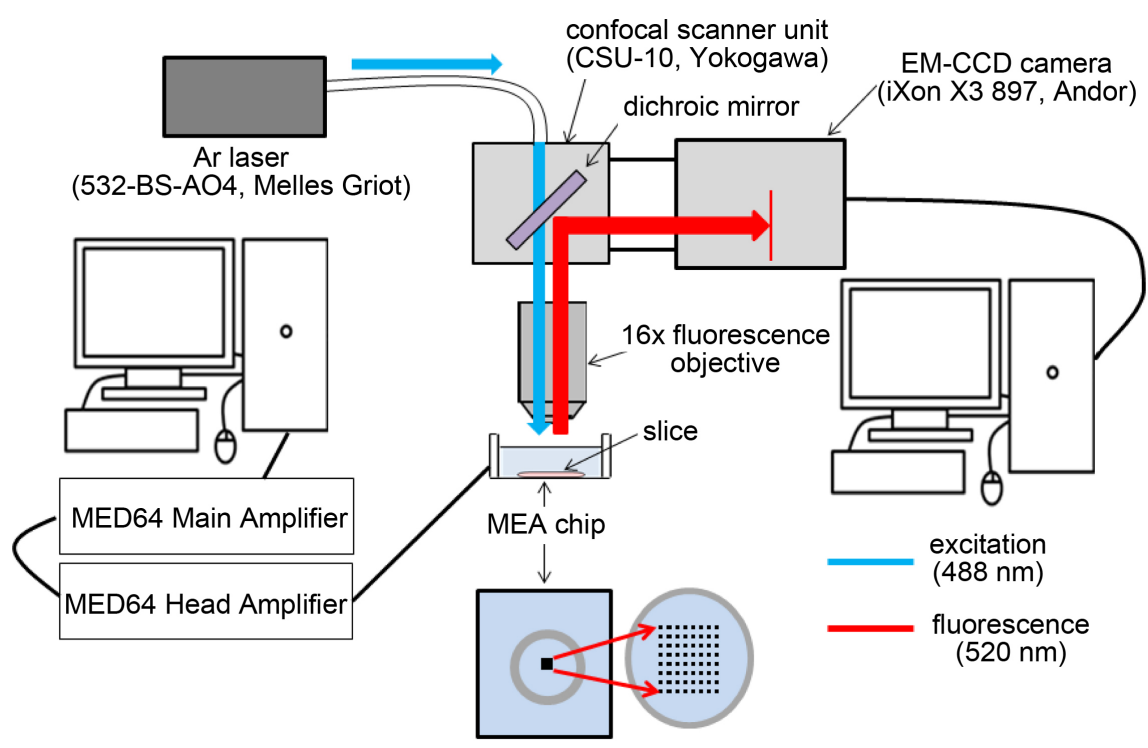

Figure 1. Schematic illustration of the present apparatus. It was constructed by combining the MEA system and laser confocal calcium imaging. The detail is described in the text. 


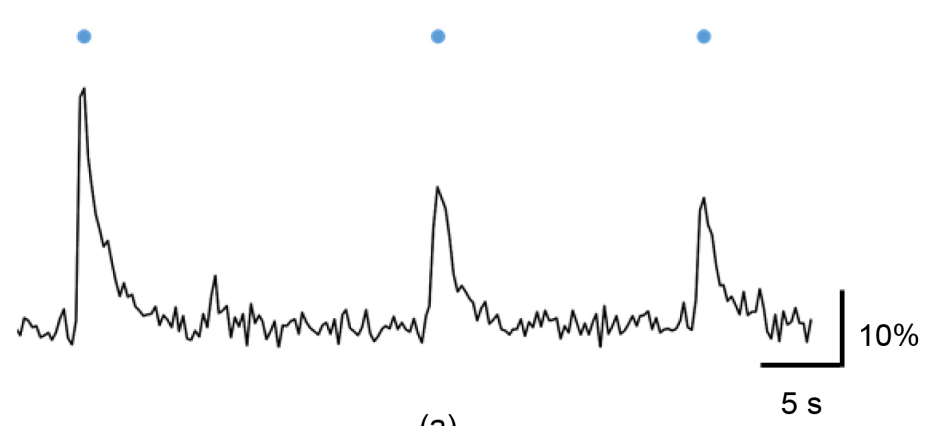

(a)

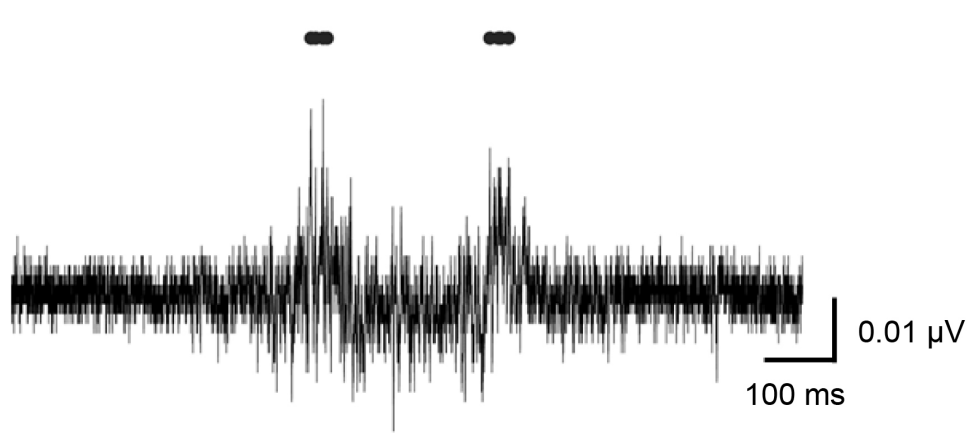

(b)

Figure 2. Time courses of (a) the calcium signals and (b) electric signals. The blue and black dots are detected peaks of the calcium signals and electric signals, respectively.

calcium signals in acute mouse hippocampal slices. As the calcium indicator dye, we used Cal-520 which is recently developed and exhibits a large fluorescence change [23] [24]. Although we used an upright microscope in the present study, an inverted microscope could be suitable for another study. Especially in such a case, we must detect the calcium signals through the glass MEA chip and therefore Cal-520 will be preferable. In our previous experiments, the average peak amplitude of calcium signals and SNR of Cal-520 were estimated to be about $11.5 \%$ and 3.4, respectively, while those of Oregon green which has been much often used for laser confocal calcium imaging [21] [22] were estimated to be 6.5\% and 2.0 (not published data).

We first measured spontaneous electric signals and calcium signals simultaneously using the present method. Here, no stimuli were applied anywhere. Sometimes such spontaneous neural activities occurred without any stimuli. The electric signals were measured in the whole of hippocampus (Figure 3(a) (upper panel) and Figure 3(c)) and the calcium signals were measured in the CA1 region (Figure 3(a) (lower panel) and Figure 3(b)) which is shown with blue rectangles in Figure 3(a) (upper panel) and Figure 3(c). The supplemental movie can be seen in the web site (The URL is in the figure legend of Figure 3). Figure 4 shows the raster plots for the electric signals and calcium signals. The peak positions of signals are shown by black or blue dots. The electric signals in the 


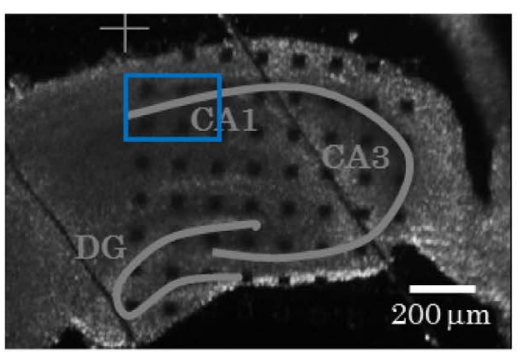

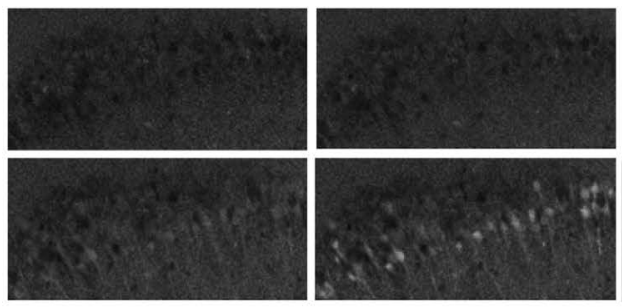

(b)

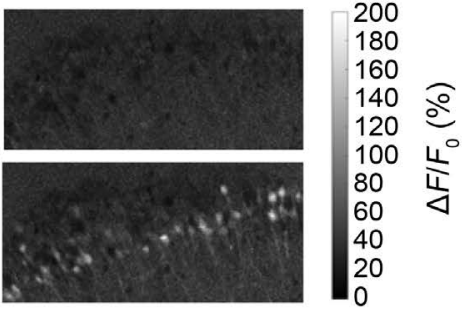

$\overline{50 \mu \mathrm{m}}$

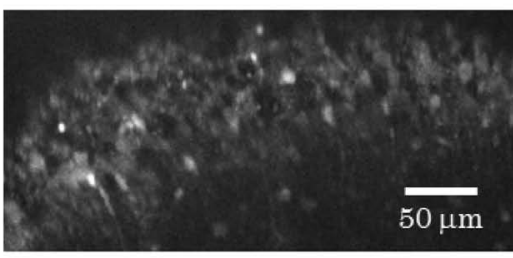

(a)

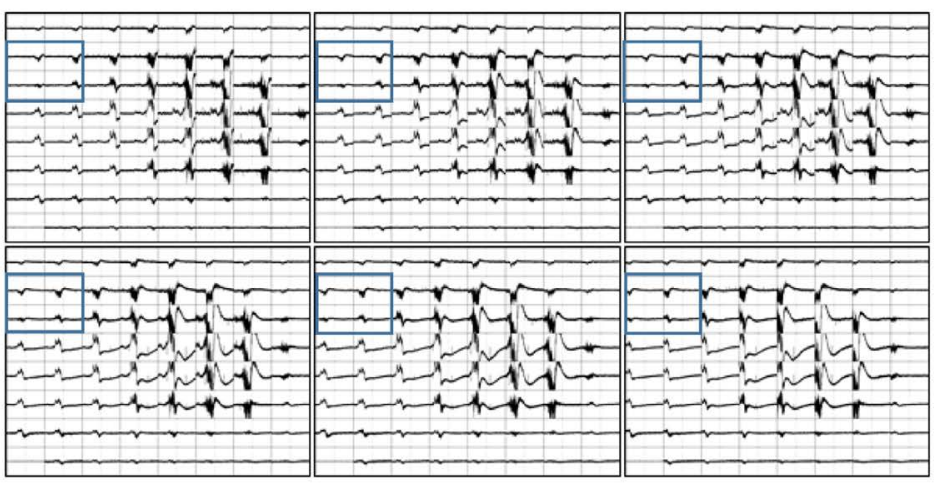

(c)

Figure 3. (a) Upper panel; A hippocampal slice on the MEA chip. The small black squares are the 64 electrodes. Lower panel; Fluorescence image of the CA1 region for laser confocal calcium imaging (b), which is shown as a blue rectangle in the upper panel and (c). (b) Consecutive images of $\Delta F / F_{0}$ in the CA1 region. The images are shown with a gray scale. The time proceeds from the upper left to lower right image at an interval of $150 \mathrm{~ms}$. (c) Consecutive electric signals from 64 MEA electrodes. 64 windows of each panel correspond to the MEA electrodes. The full scales of the horizontal and vertical axes of each window are $1 \mathrm{~s}$ and $0.1 \mu \mathrm{V}$, respectively. The time proceeds from the upper left to lower right panel at an interval of $150 \mathrm{~ms}$. The blue rectangle in each panel corresponds to each image of (b), and the image was acquired at the center time (dotted line) of each window. See also the supplemental movie (http://saitolab-chaos.com/Papers/jbbs2017/Supplemental-movie1.html; double speed reproduction).

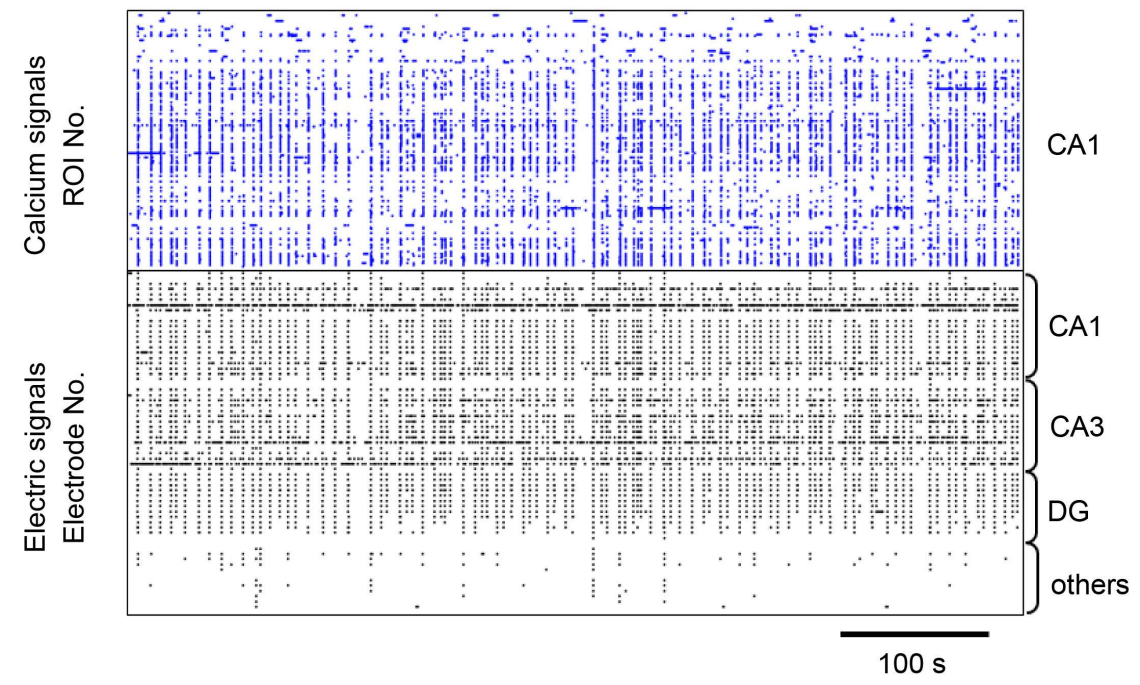

Figure 4. Raster plots for the electric signals from 64 MEA electrodes under the DG, CA3 and CA1 regions and the calcium signals from 135 ROIs in the CA1 region. The black and blue dots show the peak positions of electric signals and calcium signals, respectively. The slice is the same one used for Figure 3. 
whole of hippocampus, where larger burst-like signals were seen in the CA3 region, and the calcium signals of the CA1 region seem to occur simultaneously. Expanding the time scale, however, the calcium signals occur with a time delay of a few hundred of milliseconds from the electric signals (Figure 5). On the other hand, no distinct time delay was detected among the electric signals of those regions and therefore it was unclear where the spontaneous neural activities originated.

We next measured the electric signals and calcium signals during the LTP measurement. The LTP was induced by applying the theta burst stimulation to an electrode under the Shaffer collateral. In the theta burst stimulation, the burst of 4 pairs of pulses (each pulse strength: $-100 \mu \mathrm{A}$ or $+100 \mu \mathrm{A}$, each pulse width: $0.1 \mathrm{~ms}$ ) with $10 \mathrm{~ms}$ interval was repeated 10 times with $200 \mathrm{~ms}$ interval, and the train of 10 bursts was repeated 20 times with $5 \mathrm{~s}$ interval. The electric signals were measured for the whole of hippocampus, and the LTP induction was confirmed by an increase in the slope of fEPSP in the CA1 region for the test stimulus (a pair of pulses (each pulse strength: $-100 \mu \mathrm{A}$ or $+100 \mu \mathrm{A}$, each pulse width: $0.1 \mathrm{~ms}$ )) repeated with $20 \mathrm{~s}$ interval to the Shaffer collateral (Figure 6), where the calcium signals were measured simultaneously. Figure 7 shows consecutive images of calcium signals in the CA1 region during the LTP measurement. The supplemental movies can be seen in the web site (The URL is in the figure legend

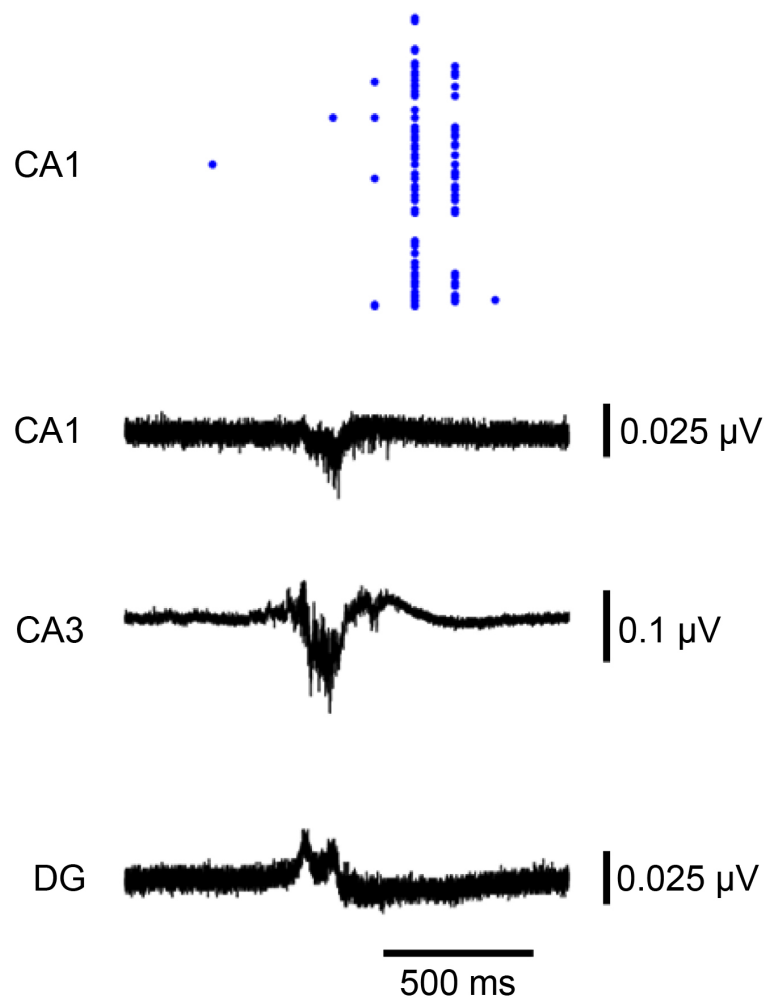

Figure 5. A time relation between the electric signals and the peak positions (blue dots) of calcium signals. The electric signals were measured by one of electrodes under the DG, CA3 or $\mathrm{CA} 1$ region. The slice is the same one used for Figure 3. 


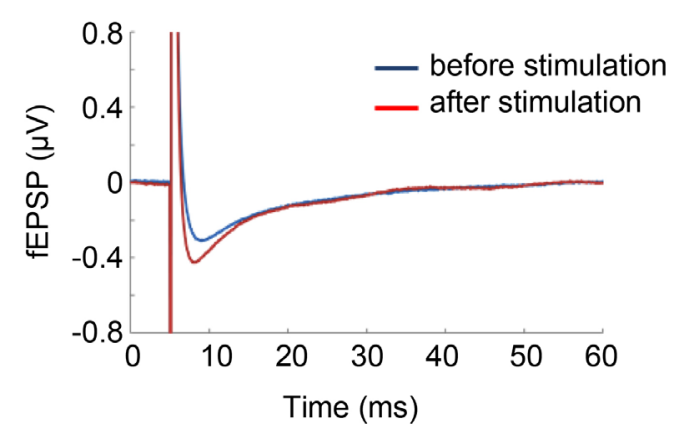

(a)

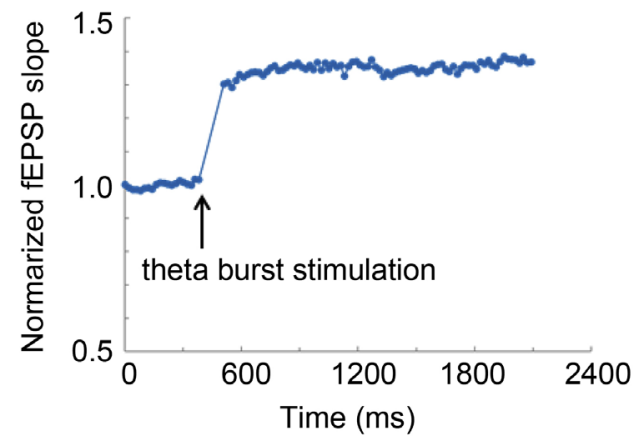

(b)

Figure 6. (a) fEPSPs before and after the theta burst stimulation; (b) Change in the fEPSP slope by the theta burst stimulation. The slope is normalized by that before the stimulation.
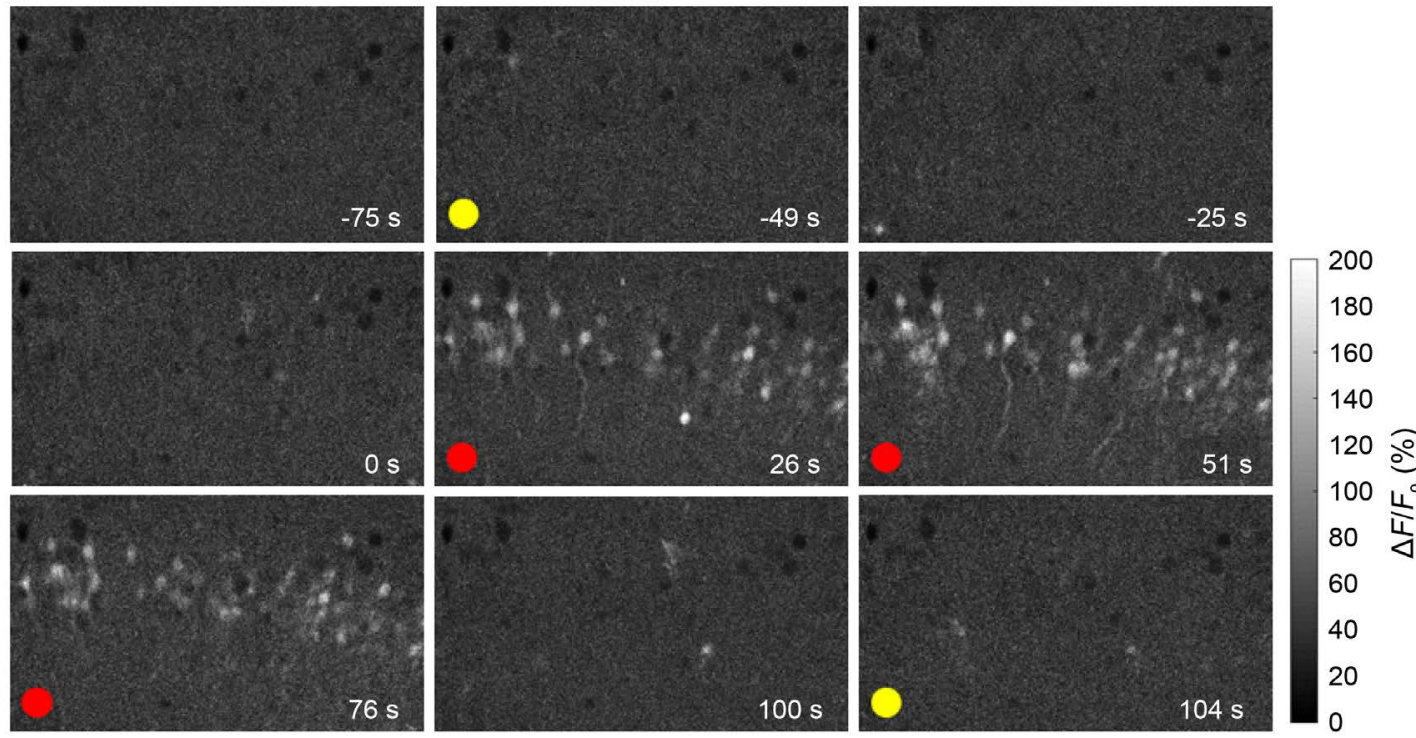

$50 \mu \mathrm{m}$

Figure 7. Consecutive images of $\Delta F / F_{0}$ in the CA1 region during the LTP measurement. The images are shown with a gray scale. The time from the onset of the theta burst stimulation is shown in each image. The yellow circle shows the timing for application of the test stimulus, and the red circle shows the timing for application of a burst train in the theta burst stimulus. No circle shows the timing without any stimuli. The slice is the same one used for Figure 6. See also the supplemental movie (http://saitolab-chaos.com/Papers/jbbs2017/Supplemental-movie2.html; double speed reproduction). 
of Figure 7). Figure 8 shows the raster plots of the calcium signals. In this slice, obvious spontaneous neural activities could not be seen; the average peak number of calcium signals was $0.82 / \mathrm{min}$ per one ROI before the theta burst stimulation. The test stimuli did not also induce more calcium signals. However, as expected, the calcium signals remarkably increased during the theta burst stimulation; the average peak number of calcium signals was $7.82 / \mathrm{min}$ per one ROI. After the theta burst stimulation, it became $0.83 / \mathrm{min}$ per one ROI, which did not much increase compared with that before the stimulation.

\section{Conclusions}

In this study, we constructed a measurement apparatus combining the MEA system and laser confocal calcium imaging. For the calcium indicator dye, we used Cal-520 which is recently developed and exhibits a large fluorescence change. By the present method, we simultaneously measured extracellular electric signals and intracellular calcium signals in acute mouse hippocampal slices. We showed the availability of the present method by obtaining the following results:

1) The calcium signals in the CA1 region occur with a time delay of a few hundred of milliseconds from the electric signals in the DG, CA3 and CA1 regions, while no distinct time delay was detected among the electric signals of those regions.

2) During the LTP induction by applying the theta burst stimulation to the Shaffer collateral, the calcium signals in the CA1 region remarkably increased as expected, while the calcium signals after the theta burst stimulation did not much increase compared with those before the stimulation.

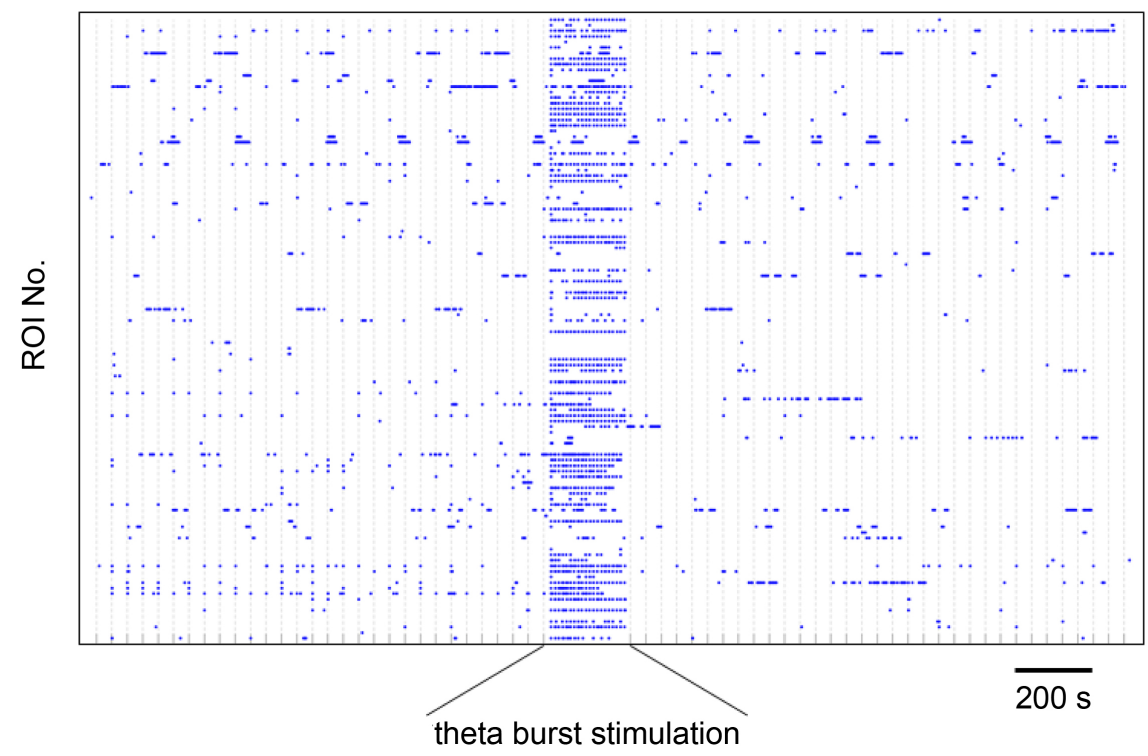

Figure 8. Raster plots for the calcium signals from 112 ROIs in the CA1 region during the LTP measurement. The tick marks on the horizontal axis show the timings for the test stimuli. The blue dots show the peak positions of calcium signals. The slice is the same one used for Figure 6. 
To elucidate the brain function, we need to measure complicated interactions among electric neural activities, intracellular calcium signals, intercellular communications by neurotransmitters, and so on. The present method will be the first step to realize it, and we hope that the present method will contribute to the future studies on the brain function including the LTP mechanism in the hippocampus.

\section{Acknowledgements}

This study was supported by Nihon University Research grant (Total Research 14-002, 15-002 to M.S.).

\section{References}

[1] Kandel, E.R. and Schwartz, J.H. (2013) Principles of Neural Science. 5th Edition, McGraw-Hill, New York, 1502.

[2] Lynch, G., Larsom, J., Keslo, S., Barrionuevo, G. and Shutter, F. (1983) Intracellular Injection of EGTA Block Induction of Hippocampal Long-Term Potentiation. Nature, 305, 719-721. https://doi.org/10.1038/305719a0

[3] Malenka, R.C., Kauer, J.A., Zucker, R. and Nicoll, R.A. (1988) Postsynaptic Calcium Is Sufficient for Potentiation of Hippocampal Synaptic Transmission. Science, 242, 81-84. https://doi.org/10.1126/science.2845577

[4] Regehr, W.G. and Tank, D.W. (1990) Postsynaptic NMDA Receptor-Mediated Calcium Accumulation in Hippocampal CA1 Pyramidal Cell Dendrite. Nature, 345, 807-810. https://doi.org/10.1038/345807a0

[5] Müller, W. and Conner, J.A. (1991) Dendritic Spines as Individual Neuronal Compartments for Synaptic $\mathrm{Ca}^{2+}$ Responses. Nature, 354, 73-76. https://doi.org/10.1038/354073a0

[6] Pine, J. (1980) Recording Action Potentials from Cultured Neurons with Extracellular Microcircuit Electrodes. Journal of Neuroscience Methods, 2, 19-31. https://doi.org/10.1016/0165-0270(80)90042-4

[7] Jimbo, Y., Tateno, T. and Robinson, H.P. (1999) Simultaneous Induction of Pathway-Specific Potentiation and Depression in Networks of Cortical Neurons. Biophysical Journal, 76, 670-678. https://doi.org/10.1016/S0006-3495(99)77234-6

[8] Oka, H., Sugimoto, K., Ogawa, R., Sugihara, H. and Taketani, M. (1999) A New Planar Multielectrode Array for Extracellular Recording: Application to Hippocampal Acute Slice. Journal of Neuroscience Methods, 93, 61-67. https://doi.org/10.1016/S0165-0270(99)00113-2

[9] Alhebshi, A.H., Gotoh, M. and Suzuki, I. (2013) Thymoquinone Protects Cultured Rat Primary Neurons against Amyloid Beta-Induced Neurotoxicity. Biochemical and Biophysical Research Communications, 433, 362-367. https://doi.org/10.1016/j.bbrc.2012.11.139

[10] Odaira, A., Saitoh, Y., Alhebshi, A.H., Gotoh, M. and Suzuki, I. (2014) Long-Term Electrophysiological Activity and Pharmacological Response of a Human Induced Pluripotent Stem Cell-Derived Neuron and Astrocyte Co-Culture. Biochemical and Biophysical Research Communications, 443, 1176-1181. https://doi.org/10.1016/j.bbrc.2013.12.142

[11] Ibi, D., Nitta, A., Ishige, K., Cen, X., Ohtakara, T., Nabeshima, T. and Ito, Y. (2010) Piccolo Knockdown-Induced Impairments of Spatial Learning and Long-Term Potentiation in the Hippocampal CA1 Region. Neurochemistry International, 56, 
77-83. https://doi.org/10.1016/j.neuint.2009.09.004

[12] Ooishi, Y., Kawato, S., Hojo, Y., Hatanaka, Y., Higo, S., Murakami, G., Komatsuzaki, Y., Ogiue-Ikeda, M. and Kimoto, T. (2012) Modulation of Synaptic Plasticity in the Hippocampus by Hippocampus-Derived Estrogen and Androgen. The Journal of Steroid Biochemistry and Molecular Biology, 131, 37-51. https://doi.org/10.1016/j.jsbmb.2011.10.004

[13] Uchimoto, K., Miyazaki, T., Kamiya, Y., Mihara, T., Koyama, Y., Taguri, M., Inagawa, G., Takahashi, T. and Goto, T. (2014) Isoflurane Impairs Learning and Hippocampal Long-Term Potentiation via the Saturation of Synaptic Plasticity. Anesthesiology, 121, 302-310. https://doi.org/10.1097/ALN.0000000000000269

[14] Orbach, H.S., Cohen, L.B. and Grinvald, A. (1985) Optical Mapping of Electrical Activity in Rat Somatosensory and Visual Cortex. The Journal of Neuroscience, 5 , 1886-1895.

[15] Delaney, K.R., Gelperin, A., Fee, M.S., Flores, J.A., Gervais, R., Tank, D.W. and Kleinfeld, D. (1994) Waves and Stimulus-Modulated Dynamics in an Oscillating Olfactory Network. Proceedings of the National Academy of Sciences of the United States of America, 91, 669-673. https://doi.org/10.1073/pnas.91.2.669

[16] Okada, K., Kanzaki, R. and Kawachi, K. (1996) High-Speed Voltage-Sensitive Dye Imaging of an in Vivo Insect Brain. Neuroscience Letters, 209, 197-200. https://doi.org/10.1016/0304-3940(96)12646-X

[17] Watanabe, S., Shimozono, S. and Kirino, Y. (2004) Optical Recording of Oscillatory Neural Activities in the Molluscan Brain. Neuroscience Letters, 359, 147-150. https://doi.org/10.1016/j.neulet.2004.01.063

[18] Yoshida, R., Iwamoto, A. and Nagahama, T. (2001) Calcium Imaging for Detection and Estimation of Spike Activities in Aplysia Neurons. Zoological Science, 18, 631-643. https://doi.org/10.2108/zsj.18.631

[19] Sato, S., Osanai, H., Monma, T., Harada, T., Hirano, A., Saito, M. and Kawato, S. (2004) Acute Effect of Corticosterone on N-Methyl-D-Aspartate Receptor-Mediated $\mathrm{Ca}^{2+}$ Elevation in Mouse Hippocampal Slices. Biochemical and Biophysical Research Communications, 321, 510-513. https://doi.org/10.1016/j.bbrc.2004.06.168

[20] Ikegaya, Y., Aaron, G., Cossart, R., Aronov, D., Lample, I., Ferster, D. and Yuste, R. (2004) Synfire Chains and Cortical Songs: Temporal Modulates of Cortical Activity. Science, 304, 559-564. https://doi.org/10.1126/science.1093173

[21] Ikegaya, Y., Bon-Jero, M.L. and Yuste, R. (2005) Large-Scale Imaging of Cortical Network Activity with Calcium Indicators. Neuroscience Research, 52, 132-138. https://doi.org/10.1016/j.neures.2005.02.004

[22] Takahashi, N., Sasaki, T., Usami, A., Matsuki, N. and Ikegaya, Y. (2007) Watching Neuronal Circuit Dynamics through Functional Multineuron Calcium Imaging (fMCI). Neuroscience Research, 58, 219-225. https://doi.org/10.1016/j.neures.2007.03.001

[23] Ellefsen, K.L., Settle, B., Parker, I. and Smith, I.F. (2014) An Algorithm for Automated Detection, Localization and Measurement of Local Calcium Signals from Camera-Based Imaging. Cell Calcium, 56, 147-156. https://doi.org/10.1016/j.ceca.2014.06.003

[24] Tada, M., Takeuchi, A., Hashizume, M., Kitamura, K. and Kano, M. (2014) A Highly Sensitive Fluorescent Indicator Dye for Calcium Imaging of Neural Activity in Vitro and in Vivo. European Journal of Neuroscience, 39, 1720-1728. https://doi.org/10.1111/ejn.12476 
Submit or recommend next manuscript to SCIRP and we will provide best service for you:

Accepting pre-submission inquiries through Email, Facebook, LinkedIn, Twitter, etc. A wide selection of journals (inclusive of 9 subjects, more than 200 journals)

Providing 24-hour high-quality service

User-friendly online submission system

Fair and swift peer-review system

Efficient typesetting and proofreading procedure

Display of the result of downloads and visits, as well as the number of cited articles Maximum dissemination of your research work

Submit your manuscript at: http://papersubmission.scirp.org/

Or contact jbbs@scirp.org 